\title{
A narrativa literária: um jogo de espelhos ${ }^{1}$
}

Ruth Silviano Brandão Lopes

$U F M G$

Resumo: O ensaio desenvolve uma reflexão teórica, explorando a metáfora do espelho, tradicionalmente relacionada com o conceito de mimese, $e$ demonstrando sua pertinência para a compreensão de conceitos literários, tais como o de dialogismo e de intertextualidade, assim como de certas instâncias narrativas, como a de autor e a de narrador.

Palavras-chave: Teoria da Literatura, espelho, mimese.

É possível pensar a narrativa literária através da palavra espelho, que pode ser apreendida como uma grande metáfora do reflexo, da imitação, da mímese, neste caso colocando-se uma das questões mais antigas da Literatura: sua relação com o Real, ou, mais propriamente, como o conceito de Real.

Entretanto, espelho é também tudo aquilo que estabelece relações, sejam elas simétricas, assimétricas ou inversas. Tudo aquilo que cria o duplo, que supõe duas cenas, duas articulações, passagem para uma outra dimensão, que,

1. Este texto foi apresentado como conferência no Seminário Geral promovido pela Comissão Científica do Círculo Psicanalítico de Minas Gerais, a 25 de agosto de 1983, sobre "Literatura e Psicanálise", quando se abordou o seguinte tema: "Modos e formas do espelho literário". 
sendo outra, entretanto, reflete a primeira, nunca se esgotando como pura repetição. Essas múltiplas imagens fazem-se no nível da fabulação, da história ou do enredo e também no nível do próprio discurso, nem sempre levado em conta pelo leitor já fascinado pela ficção, já do outro lado do espelho, mas sem consciência de ter feito essa estranha travessia.

Escolhido esse caminho, vai-me interessar pensar aqui sobre o espelho, não só como tema recorrente da literatura, herdeiro das narrativas míticas, entre as quais destaca-se de forma privilegiada a história de Narciso, mas também espelho como processo, jogo, maquinismo ou engenho, artefato, bricolage.

Desmistificada pelo pensamento contemporâneo a ilusão de um sujeito inteiro, sem cisões, original, desmistifica-se também a obra literária como pura inspiração privilegiada de um autor iluminado, espécie de deus ex machina, criador a partir de zero, como queriam os românticos. Depois dos estudos de M. Bakhtine sobre a obra de Dostoiévski, mais tarde desenvolvidos por Julia Kristeva e outros críticos, pensa-se o texto literário antes como mosaico de textos, eco e transformação de outras vozes narrativas, que vão produzir um espaço discursivo tensional, às vezes fragmentário e problematizador.

O texto literário é, então, o lugar da confluência de reflexos, complexo de espelhos que refletem outros espelhos. Ora, o espelho pode ser plano, côncavo, convexo, pode inverter, deformar, transformar, sendo sempre um espaço de encenação, lugar da produção de um espetáculo.

A consciência cada vez mais aguda da Poética contemporânea desse interminável processo canibalístico de apropriação e travestimento de discursos às vezes residuais, feita de forma consciente e/ou inconsciente, levou o critico francês Gérard Genette a desenvolver uma teoria da transtextualidade, que consiste nessa interrelação textual, que une um texto a outro, ou um hipotexto a um hipertexto, de forma implícita ou explícita. Segundo ele, a hipertextualidade ou a relação de derivação que existe entre as obras literárias é

evidentemente um aspecto universal da literaridade: não existe obra literária que, num certo grau e de acordo com a leitura, não evoque alguma outra e, nesse sentido, todas as obras são hipertextuais. ${ }^{2}$

2. GENETTE. Palimpsestes, p. 16. 
Genette usa também o termo arquitextualidade como uma das formas de transtextualidade, tomada como relação do texto com um conjunto de categorias que envolvem gênero e formas de enunciação, entre outras. No entanto, esse termo arquitextualidade, considerado de forma restrita pelo autor, parece-me muito sugestivo e tomo-o num campo mais amplo, por evocar, de um ponto de vista genético, o processo arqueológico que torna possível perceber o texto literário sempre em relação a outros, em camadas arcaicas, complexas e no entanto sempre relativas a um mesmo solo, a um mesmo terreno de criações que se vão sedimentando e transformando. Metaforicamente, esse mecanismo é um jogo de espelhos múltiplos, que não é pura reduplicação, mas um maquinismo onde fragmentos textuais remetem a outros textos, outras vozes. Esse diálogo permanente e fecundo longe de ser algo que vai propiciar um imobilismo literário é antes um permanente processo dialético, em que novas mensagens são produzidas em novos códigos, em que o já dito vai ser problematizado, transgredido dentro de um diferente contexto. Segundo Laurent Jenny,

a análise do trabalho intertextual mostra bem que a pura repetição não existe, ou, por outras palavras, que esse trabalho exerce uma função crítica sobre a forma. Isto, quer a intencionalidade seja explicitamente crítica - como na sátira menipéia -, ou não. Se o vanguardismo intertextual é freqüentemente sábio, é porque está ao mesmo tempo consciente do objeto sobre o qual trabalha, e das recordações culturais que o dominam. O seu papel é re-enunciar de modo decisivo certos discursos cujo peso se tornou tirânico. ${ }^{3}$

Para ilustrar rapidamente essa afirmação, lembro aqui a composição parodística de Oswald de Andrade - Canto de regresso à pátria - em que o verso "Minha terra tem palmares" ecoando o célebre "Minha terra tem palmeiras" de Gonçalves Dias, lírico e ingênuo, vai modificar lucidamente a visão de um Brasil edênico e inocente.

O processo de imitação referido por Genette supõe a constituição de um modelo do texto a ser imitado, que vai funcionar como mediação para a nova construção textual. Essa mediação vai ser elemento fundamental na criação de novos textos e vai estar sempre presente, de forma consciente ou não na sua

3. JENNY. A estratégia da forma. In: Intertextualidades, p. 44. 
feitura. A obra literária, então, é impensável fora de um sistema, ao qual ela se ajusta ou que ela transgride.

Não refletindo apenas outras obras, numa dimensão externa, a narrativa literária pode constituir-se de espelhos internos, ao nível do enunciado ou da enunciação. A reflexão interna de um texto pode dar-se por micronarrativas que desdobram a narrativa principal, pertencendo a ela como enunciados metonímicos, que podem ter uma função variada, sempre expandindo-lhe a dimensão semântica. ${ }^{4}$ Processo semelhante é conhecido na pintura. Nas obras dos holandeses do século XVII, por exemplo, em que um pequeno espelho convexo colocado em determinada posição em relação à cena pintada tem uma função de redobro ou de captação do que normalmente seria excluído do olhar do espectador. Ou, diferentemente, no caso especial das Meninas de Velázquez, tal como foi estudado por Michel Foucault, ${ }^{5}$ em que o espelho plano colocado no fundo da tela problematiza o conceito de representação e o próprio lugar do sujeito da representação e do espectador. Esse mecanismo de especularização pode ser relacionado com a obra literária e os problemas que ela oferece.

A relação do autor com seu próprio texto já é uma construção que implica reciprocidade. O narrador/protagonista de uma história pode ser duplo de uma personagem que conta uma outra história que, por sua vez, reflete a primeira, estabelecendo-se relações de homologia entre as duas. O narrador usa de vários recursos para criar essa ficção da multiplicidade de vozes.

Para Todorov, ${ }^{6}$ falando do dialogismo estudado por Bakhtine, existe uma grande diferença entre o discurso literário e as outras formas discursivas que também supõem a polêmica interior ou o confronto de vozes. É que no texto literário, o dialogismo é inerente, interno, presente em todas as suas dimensões, criado propositalmente com os recursos do próprio discurso.

O autor literário é aquele que, no plano ficcional, cria uma segunda voz, que encena a primeira, atuando sobre o próprio discurso, sua matéria prima, reelaborada com elementos também discursivos. Nesse sentido, ele é dramaturgo que distribui o discurso a outras vozes.

4. Ver o conceito de narrativa especular e "mise en abyme" em DÄLLENBACH. Le récit speculaire.

5. FOUlCAUlt. Las Meninas. In: As palavras e as coisas.

6. TODOROV. Intertextualité. In: Mikhail Bakhtine le principe dialogique suivi de Écrits du Cercle de Bakbtine. 
Para Bakhtine,

o objeto fundamental, específico do gênero romanesco, aquele que produz originalidade estilística é o homem falante e seu discurso. Não é a imagem do homem em si mesma que é característica do gênero romanesco, mas precisamente a imagem da linguagem. ${ }^{7}$

Ainda Bakhtine,

todo romance é, em graus variáveis, um sistema dialógico de imagens de línguas, de estilos, de consciências concretas e inseparáveis da linguagem. A linguagem, no romance, não representa apenas: ela serve também de objeto de representação. O discurso romanesco é sempre auto-crítico.

A narrativa literária é também o lugar onde se encenam as ilusões, a ficção, usando como no teatro todo um maquinismo de verossimilhança, que faz a ficção parecer real.

Max Milner, em La fantasmagorie, refere-se à relação que existe entre a arte e os avanços técnicos de seu tempo e fala das experiências óticas do século XIX que vão de alguma forma aparecer na literatura, especialmente na fantástica. A fantasmagoria foi uma encenação, um espetáculo criado pelo francês Etienne Gaspard Robertson, para através de um jogo de espelhos, luzes e sombras, criar a ilusão do movimento, da aparição de figuras e cenas. Diz Milner que esses jogos de ilusão vão influenciar a literatura do século XIX e chama o texto literário, principalmente o descritivo, de máquina de fazer ver. Ver o quê? Ver a ficção, criações fantasmagóricas e fantasmáticas, capazes de capturar o desejo do leitor, que vai desejar um texto que é também portador de um desejo. O texto fantástico, criador privilegiado de ilusões, alucinações, mobilizador de desejos e temores do leitor, propiciador de estranha inquietude referida por Freud, gerador de fantasmas e duplos, é o tipo de narrativa que vai de forma mais clara e exemplar oferecer ao crítico literário oportunidade de localizar os mecanismos da criação da ilusão, semelhantes aos da fantasmagoria de Robertson.

7. TODOROV. Intertextualité. In: Mikhail Bakbtine le principe dialogique suivi de Écrits du Cercle de Bakhtine, p. 103.

8. TODOROV. Intertextualité. In: Mikhail Bakhtine le principe dialogique suivi de Écrits du Cercle de Bakbtine, p. 103. 
No que se refere ao narrador, vê-se como ele vai-se deslocando, delegando sua voz a personagens donos de um discurso não digno de confiança, porque vindo de loucos ou de elementos presos de um estado de extrema agitação e espanto.

Nesse jogo, o lugar do autor/narrador é sempre móvel, na medida em que ele transfigura-se em personagens, representa a linguagem, sua enunciação sendo sempre dupla. Passando pelo limiar do espaço ficcional, ele opera um rito de passagem, que supõe travestimento, fingimento, num processo de ilusionismo que vai criar a primeira dimensão da ambiguidade entre realidade e ficção. Essa entidade flutuante pode movimentar-se nos vários planos da narrativa, fazendo ecoar essas vozes ficcionais ou ecos nem sempre reconhecidos como tal.

Enfim, a imagem do espelho não leva necessariamente ao espelho do Narciso mítico, pura reduplicação, imagem de seu desejo, mas a um jogo complexo de reflexões. Mesmo o narrador da primeira pessoa, que se quer contar, dividindo-se em sujeito do enunciado e sujeito da enunciação, narrador e personagem ao mesmo tempo, relacionando-se de forma dual com sua escritura, pode, através dela, percorrer múltiplos caminhos, transformando sua face discursiva de forma às vezes imprevista para ele mesmo.

\section{Literary narrative: a game of mirrors}

Abstract: This article offers a theoretical discussion of the metaphor of the mirror, traditionally related to the notion of mimesis, and demonstrates its relevance to the understanding of literary concepts such as dialogism and intertextuality, as well as to some narrative elements, such as author and narrator.

Keywords: Literary Theory, mirror, mimesis. 
Belo Horizonte, p. 1-171

$$
\text { Referências }
$$

DÄLLENBACH, L. Le récit speculaire. Paris: Seuil, 1977.

FOUlCAUlT, M. Las Meninas. In: As palavras e as coisas. Lisboa: Portugália, s. d. GENETTE, G. Palimpsestes. Paris: Seuil, 1982.

JENNY, L. A estratégia da forma. In: JENNY et al. Intertextualidades. Coimbra: Almedina, 1979.

MILNER, Max. La fantasmagorie. Paris: PUF, 1982.

TODOROV, T. Intertextualité. In: Mikhail Bakbtine le principe dialogique suivi de Écrits du Cercle de Bakbtine. Paris: Seuil, 1981. 